\title{
Resilience as a moderator of Stress and Burnout: a study of Women Social Workers in India
}

Running head: Resilience as a moderator of Stress and Burnout

Authors: Selwyn Stanley ${ }^{1}$; Gnanapragasam Buvaneswari Mettilda ${ }^{2}$; Arumugam Meenakshi ${ }^{3}$

Affiliations: ${ }^{1}$ School of Social Work \& Social Policy, University of Strathclyde, Glasgow, UK (Corresponding Author)

${ }^{2}$ Department of Social Work, Cauvery College for Women, Tiruchirappalli, India.

${ }^{3} \mathrm{PhD}$ Student, Cauvery College for Women, Tiruchirappalli, India.

\section{Author biographies:}

1Selwyn Stanley has been a social work educator for more than three decades and has published extensively in areas relating to impact of alcohol misuse on the family, social work education and professional practice.

${ }^{2}$ Mettilda, G.B., has been a social work educator for 22 years and her research interests are in mental health, gender and women studies, ageing and family dynamics

${ }^{3}$ Meenakshi, A., is a PhD student of Social Work, Cauvery College for Women, India. Her area of specialisation is Medical and Psychiatric social work

Declaration of interest: The authors report no declarations of interest. 


\section{Resilience as a moderator of Stress and Burnout: a study of Women Social}

Workers in India

\section{Abstract}

It is well acknowledged that social workers encounter a considerable amount of work stress. Besides dealing with service users in complex life situations, social workers in India work in a context characterised by organisational constraints, poor pay scales and larger issues relating to the lack of recognition and ambivalence relating to its status as a profession. This quantitative study explored issues such as the experience of stress, resilience and the professional quality of life in women social workers in Tiruchirappalli, South India by administering standardised instruments. Implications for intervention have been discussed in the light of the findings.

Keywords: Stress, Resilience, Compassion satisfaction, Burnout, Social Workers, India 


\section{Introduction}

Social work is a high-stress profession that involves working with people who face complex and challenging life situations. There has been a considerable amount of literature on stress and burnout experienced by social work practitioners, mostly generated in Western countries. Depression, burnout, and higher levels of sickness have been attributed to the high levels of stress reported in social workers (Schraer, 2015; Willems, 2014). Research on stress and burnout in social work has broadly followed three strands of investigation; exploration of the influence of organisational factors, practitioner characteristics and client attributes. Some organisational factors that influence stress have been identified as low organisational support, limited resources and poor IT systems (Beer, 2016). Poor pay, elevated caseloads and the blame culture have been associated with retention issues in social workers (McGregor, 2014). The interaction between high work demands, low levels of control and poor managerial support have been related to social worker stress (Ravalier, 2018) and the combination of high work pressures, lack of control over decision making and resources are detrimental to their job satisfaction (Wilberforce et al., 2014). Poor retention rates and/or burnout in social workers have also been related to the extent to which they can exercise professional discretion and the amount of administrative functions that they undertake (Moriarty, Baginsky and Manthorpe, 2015). Many social workers feel that the negative aspects of the job hinder their ability to effectively perform their work, causing burnout (Morazes et al., 2010). Practitioner attributes such as self-esteem, internal locus of control, general selfefficacy, extraversion, conscientiousness, agreeableness, hardiness and emotional stability have been negatively associated with emotional exhaustion and depersonalization in social workers (Alarcon, Eschelman and Bowling, 2009). Working with clients often exposes the social worker to role conflict in terms of client advocacy on the one hand and meeting agency needs on the other (Lloyd, King and Chenoweth, 2002). Having a large number of clients with post-traumatic stress disorder (PTSD), trauma issues or those considered as being 'high risk' has been associated with increased burnout rates (Craig and Sprang, 2010; Dillenburger and Myers, 2011). The degree of the client's disability has been statistically significantly related to burnout scores (GrayStanley and Muramatsu, 2011). Many of these observations made in the Western literature are universal in nature; faced by social 
workers the world over and hold true in the Indian context as well. However, the nature of social work practice in India can be differentiated from that in the West owing to several contextual factors that are unique to the country.

Social work in India does not enjoy the kind of professional standing that it does in the Western world and has not been formally recognised as a profession (Siddiqui, 2001). There is a contention that social work is only a 'semi-profession' as it lacks awareness and recognition from major stakeholders including the Government (Nair, 2015). This is largely because it is not underpinned by legislative sanction and there is no apex regulatory body that maintains professional quality and standards, accredits training institutions or licenses practitioners (Chandran, 2017). The title of 'social worker' itself is not protected and consequently is used rather loosely, often by those with no formal qualifying training (Weiss-gal and Welbourne, 2008). The bulk of practice happens in the third sector in a variety of settings that include mental health, women and child welfare, working with the elderly and community development projects in villages and slums (Stanley, 2006). The majority of social workers find employment in local, national or international nongovernmental organisations (NGOs). Work conditions frequently tend to be arbitrary and ill-defined. Pay scales are low and one's employment tenure often depends on the whims of the employer. Working hours are determined by tasks and activities rather than fixed predetermined daily hours. The job profile is often not clearly specified, and the social worker may be expected to perform other tasks that are strictly not within one's professional repertoire (Stanley and Mettilda, 2015). Work is often dictated by a paucity of resources and relatively less autonomy in decision making. It must be emphasised that while this is not the situation in all agencies, this tends to be the predominant scenario in practice. Despite these working conditions, social workers perform their roles and functions admirably and take pride in the contribution that they make in improving the life of the people and communities that they serve.

The Indian literature on issues such as stress, anxiety, resilience, coping and burnout in social work practitioners is rather scant and this study seeks to investigate the complex relationship among these variables. We were primarily interested in studying the nature of professional quality of life experienced by women social 
workers and to understand the manifestation of stress-related outcomes such as compassion fatigue and satisfaction in them.

\section{Review of Literature}

Professional quality of life as conceptualised by Stamm (2005), refers to the quality one feels in relation to one's work as a helper and incorporates both positive (Compassion Satisfaction) and negative (Compassion Fatigue) aspects.

Compassion satisfaction has been explained as the pleasure derived from being effective in the helping profession (Stamm, 2005). It encompasses the pleasure and gratitude that develops from the process of caregiving (Simon et al., 2006). Social workers experience a sense of fulfilment and satisfaction when they perceive a positive change in the people that they work with and this enhances their motivation to perform well and to continue in the profession (Jones, 2005). It has also been suggested that compared to other occupational groups, social workers can become over-committed to their jobs and may experience higher levels of conflict in terms of maintaining work-life balance (Kinman, McMurray and Williams, 2014). Compassion fatigue is a related fallout of the stress of working with people encountered by helping professionals. It refers to the negative consequences of working with traumatized clients and vicariously experiencing the effects of their life trauma (Harr and Moore, 2011). Compassion fatigue has been variously characterized as vicarious trauma, secondary trauma syndrome, posttraumatic stress syndrome and as a variant of burnout (Craig and Sprang 2010, Yoder, 2010). Stamm (2010) considers it to comprise of two components; the first concerns aspects such as exhaustion, frustration, anger and depression that are typical of burnout and the second being Secondary Traumatic Stress, which is a negative feeling driven by fear and work-related trauma.

Compassion fatigue can diminish empathic abilities and generate disinterest with the caregiving process (Adams, Boscarino and Figley, 2006). Exhaustion and reduced work efficiency have been reported in social workers experiencing compassion fatigue (Figley, 2002). Higher personal distress is associated with lower compassion satisfaction and higher compassion fatigue and burnout in clinical social workers (Thomas, 2013). Burnout has been conceptualised as a psychosocial syndrome that involves feelings of emotional exhaustion, depersonalization and diminished personal accomplishment at work (Montero-Marin et al., 2009). The intense stress 
experienced in practice has been reported to contribute to high rates of burnout in social workers (Kim and Stoner, 2008). The literature suggests that social workers' burnout can heighten psychological distress, such as depression (Evans et al., 2006; Stanley, Manthorpe, and White, 2007) and to deterioration in physical health (Kim, Ji and Kao, 2011). It is also associated with the increased likelihood of turnover intention (Kim and Stoner, 2008), absenteeism and poor retention rates in social workers (De Croon et al., 2004; Kinman and Grant, 2011).

These issues bring to the fore the importance of coping and resilience in social workers in dealing with stress, compassion fatigue and burnout experienced in work situations. Coping is viewed as a multidimensional construct that represents the behavioural and cognitive mechanisms used to manage the ongoing internal and external demands of a stressful episode and involves self-regulation (Lazarus and Folkman, 1984). The transactional stress model (Lazarus and Folkman, 1984) postulates that coping efforts may be directed towards dealing with the problem (problem-focused coping) or with its emotional accompaniments (emotion-focused coping). This model was expanded by Carver, Scheier and Weintraub (1989) to incorporate avoidance coping which is the tendency to avoid the problem as well as its emotional outcomes and is hence considered dysfunctional in nature.

Resilience is another concept frequently mentioned in the context of both stress and coping. It refers to the capacity of an individual to maintain stable functioning and to adapt in the face of significant adversity (Fletcher and Sarkar, 2013; Garci'aSecades, et al., 2016). It is a complex and multi-faceted construct that refers to a person's capacity to handle environmental difficulties, demands and high pressure without experiencing negative effects (Kinman and Grant, 2011). People with higher resilience adapt more successfully to stressful events than do those with lower resilience (Luthar, 2006). Resilient people are considered to possess characteristics that include hardiness, sense of control, emotional intelligence, optimism, hope, selfefficacy, persistence and an ability to appraise 'problems' as challenges (Collins, 2015; Grant and Kinman 2014). High levels of stress from work-related uncertainty and low levels of resilience were strongly correlated with depression and burnout in a sample of paediatric residents (Simpkin et al., 2018). The importance of emotional resilience for social workers in enabling them to manage the challenges of their role has been widely acknowledged (Laming, 2009; Munro, 2011). As an attribute, it may 
enhance positive adaptation to stressful situations that are encountered by social workers (Collins, 2008; Howe, 2008). According to the meta-model for stress, emotions and performance (Fletcher and Fletcher, 2005; Fletcher and Scott, 2010), stressors originate in an individual's environment and its effects are mediated by the processes of perception, appraisal and coping, and then consequently manifest in positive or negative responses, feeling states, and outcomes. According to this model, resilience influences the process of stress at different levels, including evaluation of stressors, metacognition in response to emotions and the selection of coping strategies (Fletcher and Sarkar, 2013). The concept of resilience has not been without criticism because of its predominant focus on the individual worker without due consideration of the structural, political, policy and organisational context which influence its manifestation (Collins, 2017).

It is evident from the review that concepts such as stress, resilience, coping, burnout and compassion fatigue are interdependent and share a complex relationship. Burnout is an important consequence of work-related stress and resilience is a crucial factor that enables people to deal more competently with stress and enhances their coping. A recent investigation posits that the degree of change in resilience predicts the magnitude of reduction in stress (Smith et al., 2018). This study primarily seeks to ascertain if resilience moderates the effect of stress in terms of adverse outcomes such as burnout in women social workers.

\section{Method}

\section{Research Design}

This study is cross-sectional in nature and survey methodology was used for data collection. A descriptive design that includes elements of a comparative nature to enable comparisons among different categories of respondents has also been incorporated. The analytical methodology followed is predominantly correlational.

\section{Measures}

(1) Questionnaire to collect socio-demographic data and work-related information.

(2) Anxiety and stress subscales of the Depression, Anxiety and Stress scales (DASS 21) by Lovibond and Lovibond (1995) were administered to the respondents. They were required to rate each item on a scale from 0 to 3 based on whether the statement applied to them or not. High scores reflect higher levels of stress and 
anxiety. Sample items for the stress scale included items such as 'I found myself getting agitated' and 'I found it difficult to relax'. The Cronbach's alpha reliability coefficient for this scale was computed to be .88 which is considered to be good (George and Mallery, 2003).

(3) The Connor and Davidson (2003) Resilience scale (CD-RISC) comprises of 25 items, each rated on a 5-point scale (0-4). It measures five factors of resilience to do with the notion of personal competence, high standards, and tenacity (Factor 1), tolerance of negative affect (Factor 2), the positive acceptance of change (Factor 3 ), and secure relationships, control (Factor 4 ) and spiritual influences (Factor 5). A cumulative resilience score can also be computed with higher scores reflecting greater resilience and can range from 0 to 100. It included items such as 'I am able to bounce back after illness or hardship'; 'I am not easily discouraged by failure'. The Cronbach's alpha in this study was calculated to be .94 and is considered as being 'excellent' (George and Mallery, 2003).

(4) The Professional Quality of Life Scale (ProQOL; Stamm, 2009) is a 30-item scale which measures the positive and negative effects experienced by those who choose to help others experiencing suffering and trauma. It is made up of three subscales: compassion satisfaction, secondary traumatic stress (STS) and burnout. The last two sub-components together make up the dimension of compassion fatigue The ProQOL asks respondents to rate how frequently they experienced certain feelings in relation to their work with clients in the last 30 days. Sample items included statements such as: 'I feel invigorated after working with those I help'; 'I feel depressed because of the traumatic experiences of the people whom I help'. The reliability coefficient for the PROQOL in this study was .87 , considered to be good (George and Mallery, 2003).

(5) Coping was assessed with the Brief Cope Scale (Carver, 1997) and has 26 items that constitute 14 subscales grouped into three categories of coping namely, problem-focused (active coping, planning, use of instrumental support), emotionfocused (use of emotional support, positive reframing, acceptance, religion, humour), and dysfunctional coping (venting, denial, substance use, behavioural disengagement, self-distraction, self-blame). Each item is answered on a four-point response scale which elicits information as to how often a particular coping strategy 
has been used to deal with stress. Examples of statements in the scale are: 'I've been using alcohol or other drugs to make myself feel better'; 'I've been getting help and advice from other people'. The reliability coefficient for this instrument (alpha) in this study was .89, considered as being 'good' (George and Mallery, 2003).

\section{Data collection}

A list of voluntary organisations registered with the District Social Welfare Board was obtained to identify NGOs in Tiruchirappalli city. Women social workers employed by these organisations were contacted after permission was obtained from the head of the organisation. The nature of the study was explained to them and their participation was solicited. Hard copies of the questionnaire were given to them at the preliminary contact and a time agreed upon for collection of completed responses. Of the 153 questionnaires thus circulated, 120 completed questionnaires were received and included for data analysis. In many instances, it involved repeated visits to collect questionnaires from potential respondents. We thus had a response rate of $78 \%$ and this data was used for analysis.

\section{Ethical considerations}

The study received ethical clearance from the Ethics Review Panel of Cauvery College, where the co-author is based. Participation was voluntary, and informed consent was obtained from all the respondents. Respondents were told that they had the option to drop out of the study at any point without any implications and would not be contacted thereafter. No personal identification data was collected and the questionnaires were anonymised.

\section{Statistical analysis}

SPSS version 24 (Statistical Package for Social Sciences; IBM Software, Armonk, NY) was used for data analysis and for generating the results of this study. The analysis involved the use of t-tests, ANOVA, Pearson's correlation and linear regression. The Bonferroni correction was applied for the ANOVA tests. It is a multiple-comparison correction used when several dependent or independent statistical tests are being performed simultaneously on the same data set and lowers the critical value at which the $F$ value is tested in order to weed out spurious results that are statistically significant (Bland and Altman, 1995). While 120 does not 
constitute a large sample, it was deemed adequate for the statistical tests executed in the study.

\section{Results}

\section{Respondents' profile}

The age of the respondents ranged from 22 to 56 years (mean=31.6) with most of them $(49.2 \%)$ being in the 20 to 30 age group. They were predominantly from a Hindu religious background (70\%) and lived in nuclear families $(76.7 \%)$ in an urban area $(61.7 \%)$. The majority of them were married (58.3and) and of these fifty-four per cent had one child. In terms of their educational background, the majority had a post-graduate social work qualification (82.5\%), 12.5\% had a higher research degree (MPhil/PhD) and the rest of them had a graduate social work degree (5\%). The majority (52.5\%) of them had specialised in Clinical Social Work (called Medical and Psychiatric social work in India), the others having specialised in Family and Child Welfare (30.8\%) and the rest in Community Development (16.7\%). In terms of their work role, the majority were designated as Counsellors (56.7\%) and the next big category was that of Field Workers (18.3\%). They classified their organisation as belonging to a Medical and Psychiatric setting (43.3\%), Family and Child Welfare $(37.5 \%)$, Educational setting (8.3\%) or as working in the field of Community Development $(10.8 \%)$. The average years of work was six years and ranged from one to thirty. For $48.3 \%$ their current employment was their first job. The majority worked for six to seven hours a day $(61.7 \%)$ and $28.5 \%$ for eight to nine hours. The mean monthly income of the sample was Rupees 11329.58 (approx. \$176) and ranged from Rs. $3000(\$ 47)$ to 55,000 (\$853). While $45 \%$ of the respondents expressed dissatisfaction with their salary, in terms of their overall job satisfaction, a high majority $(76.7 \%)$ said they were satisfied with their work. When asked about work-related problems, many of them said that social work itself was a challenging profession and some of the difficulties encountered pertained to work with stigmatised groups and victims of natural disasters. Other responses indicated difficulties in working with higher officials, politicians, and with male colleagues. When asked specifically if being a woman social worker made them face any unique issues at work, the majority denied this $(80.8 \%)$. The other respondents indicated difficulties in sometimes having to work during odd hours, concern for physical safety, problems with male colleagues who tended to be dominating and 
lack of autonomy in making work-related decisions.

\section{Insert Table 1 about here}

\section{Distribution of respondents on key study variables}

Table 1 depicts the profile of the respondents in terms of the key variables of the study. They were categorised into 'low' and 'high' groups based on the mean score for each variable. The data indicate that the majority of respondents were classified as being low on both stress (55\%) and anxiety (57.5\%). In terms of the five factors of resilience, the majority were high on Factor 1 (57.5\%), Factor $2(52.5 \%)$ and Factor 3 (53.3\%) but low on F4 (53.3\%) and F5 (57.5\%). In terms of coping strategies used, the majority were categorised as 'low' for using emotion -focused strategies (55\%) and as 'high' for problem-focused coping (52.5\%). For the professional quality of life dimension, the majority scored high for 'Compassion Satisfaction' (51.7\%). In terms of the sub-scales of the compassion fatigue scale, respondents were almost equally distributed for both burnout and secondary traumatic stress.

\section{Insert Table 2 about here \\ Age-based comparison}

Respondents were categorised into four age groups (21 to 30, 31 to 40, 41 to 50 and 51 to 60 years) and ANOVA (Analysis of Variance) tests conducted for all the key variables of the study (Table 2). As mentioned earlier the Bonferroni correction was applied to the critical $p$-value to reset the level of significance at which the $F$ values (.004) were tested. Except for factor 2 (tolerance of negative affect) and factor 5 (spiritual influences) of resilience, statistically significant differences were obtained for the remaining three. Comparison of mean scores revealed that for these three resilience factors the scores were highest for those in the 51 to 60 age group. Statistically significant differences were not obtained for the other variables of the study, in terms of the age of the respondents.

\section{Comparison based on work experience}

Respondents were classified according to their work experience into three groups ( $<10$ years; 11 to 20 years and $>21$ years) and then compared on the key variables by subjecting the data to another ANOVA, using the Bonferroni correction. Accordingly, the critical significance was set at .004 . The tests revealed no significant statistical difference with regards to any of the key variables except for 
resilience factor 3 (positive acceptance of change; $F=5.83 ; p<0.003$ ). For this factor, the highest mean score was obtained for those who had more than 20 years of work experience. Further post-hoc Scheffe tests revealed that the difference was statistically significant for the two groups with the least and highest work experience ( $<10$ years and $>21$ years).

\section{Insert Table 3 about here}

\section{Comparisons based on other background variables}

Respondents were compared based on whether they were married or single using $t$ -tests (Table 3). Analysis revealed significant differences based on their marital status in terms of the total resilience score, emotion and problem-focused coping, but not for the other key variables. Mean score comparisons show higher resilience scores for married respondents and higher means for unmarried respondents for both emotion and problem-focused coping. t-tests based on the type of family (nuclear v/s joint) did not reveal any statistically significant difference for all the key variables of the study. Comparisons based on job status (temporary v/s permanent) using t-tests revealed statistically significant differences for the overall resilience score, but not for any of the other key variables of the study. Those in permanent jobs obtained a higher mean score. When respondents were compared based on whether their current job was their first one or they had worked elsewhere before, it was seen that significant differences were seen in terms of anxiety and stress scores, but not any of the other key variables. Mean scores reveal higher levels of anxiety and stress for respondents for whom the current job was their first one.

\section{Insert Table 4 about here}

\section{Relationship between variables}

Karl Pearson's correlation coefficients were computed to assess the strength and the the direction of the relationship between variables of interest and the results are depicted in Table 4. Age showed a significant negative correlation with anxiety and positive correlation with all five resilience factors and to emotion-focused coping. Years of work correlated positively with all the five factors of resilience and negatively with secondary traumatic stress. Income correlated negatively with anxiety and positively with resilience factors 2, 3, 4 and 5 and also with dysfunctional coping and burnout. Work-stress correlated positively with anxiety but not with other variables. Anxiety entered into a positive relationship with both emotion-focused and problem-focused coping styles and with the burnout scores. The five resilience 
factors showed strong positive associations among themselves and also, to the three coping styles and with burnout. The three sub-scales of the coping scale also showed strong associations among themselves. Both emotion-focused, and problem-focused coping showed a significant positive relationship with the burnout scores.

\section{Resilience as moderator}

To ascertain if resilience moderated the association of stress with burnout, a hierarchical multiple regression analysis was done using the enter method. In the first step, a regression model was generated by treating the stress and total resilience scores as independent variables (predictors) and regressed on compassion fatigue scores, the dependent variable. The resulting model was significant $\left(R^{2}=.17, F_{(2,117)}=12.23, p<.001\right)$ and the two independent variables explained $17 \%$ of the variance in the dependent variable. To avoid spurious results owing to multicollinearity, the two independent variables were centered by subtracting the mean from the score for each respondent. To test the interaction effect between the two independent variables, a moderator variable was then computed by multiplying the centered stress and resilience scores. In the next step, this interaction term was added to the previous regression model. This model was also significant $\left(R^{2}=.23, F_{(3,116)}=11.24, p<.001\right)$. The two main effects stress $(b=$ $.29, \mathrm{SE}=.12, \beta=.21, \mathrm{t}=2.51, \mathrm{p}<.05)$ and resilience $(b=.10, \mathrm{SE}=.03, \beta=.33, \mathrm{t}=$ $4.04, p<.001$ ) emerged as significant predictors of burnout in this model. However, the interaction between stress and resilience was also significant $(b=.02, \mathrm{SE}=.01$, $\beta=.23, t=2.79, p<.05)$, indicating that the effect of stress on burnout was being moderated by the resilience scores. The increased $R^{2}$ value in the second model shows that together the stress and resilience scores (main effects) along with their interaction effect account for $23 \%$ variance in the manifestation of burnout (as against $17 \%$ variance in the first model). This increased variance can be attributed to the interaction term (anxiety-by-resilience) introduced in this model.

\section{Discussion}

The majority of respondents in this study were classified as being 'low' on both stress and anxiety. However, in the absence of comparative data relating to these two key variables, it is not possible to state if women social workers as a group in India experience higher stress and anxiety levels when compared to other similar 
professionals (e.g. nurses, counsellors etc.). Stress and anxiety levels are indeed issues of concern as work-related feelings of anxiety in social workers may lead to depression and burnout (Dollard, 2003).

With regard to resilience, respondents in this study have scored high on Factor 1 (personal competence, high standards, and tenacity), Factor 2 (tolerance of negative affect and Factor 3 (the positive acceptance of change). This indicates attributes suggestive of good resilience in the women social workers of this study. It has been evidenced by the literature that resilience in social workers may help them adapt positively to stressful situations and to enhance their professional growth (Collins, 2008; Morrison, 2007; Howe, 2008). It was interesting to observe higher resilience in married respondents than those who were single. Marriage has been said to provide emotional benefits such as reducing stress and there is evidence that married individuals display better physical and mental health than those who are single (Law and Sabarra, 2009; Lindstorm, 2009). It is difficult to offer an explanation as to why married respondents manifest higher levels of resilience in this study. One possible explanation is that as those who were married were older than their single counterparts, the positive correlation seen between age and resilience could account for this.

It was also seen that work experience correlated positively with all the dimensions of resilience and negatively with secondary traumatic stress. The literature suggests that work experience is associated with greater emotional competence (Humpel and Caputi, 2001). Years of work thus seems to positively influence resilience and with the ability to deal with secondary trauma. Income also correlated negatively with anxiety, dysfunctional coping and burnout, suggesting the need for appropriate monetary compensation to negate the influence of these variables. The positive relationship seen between income and resilience factors has been substantiated in other studies (e.g. Liu et al., 2018).

The respondents in this study were classified as being 'low' in terms of using emotion-focused coping strategies and 'high' with regard to problem -focused coping and very few of them showed the use of dysfunctional coping styles. The coping literature provides evidence that the use of emotion--focused and dysfunctional coping styles such as avoidance is associated with higher levels of 
secondary trauma (Gil and Weinberg, 2015). There is also the observation that the successful management of emotions is likely to underpin resilience in social care workers (Howe, 2008).

In terms of the professional quality of life assessed in this study, the majority of respondents were low on 'Compassion Fatigue' and scored high for 'Compassion Satisfaction'. This is a positive finding as compassion satisfaction can help to mitigate the negative impact of compassion fatigue experienced by social workers (Harr, Brice, Riley and Moore, 2014). Compassion fatigue in social workers tends to occur as a result of vicarious exposure to the suffering of clients that they interact with and can result in experiencing a reduced capacity for empathy (Adams, Boscarino, and Figley, 2006). Compassion satisfaction has also been found to mediate the negative effects of compassion fatigue and burnout and is a potential protective factor for mental health (Harr et al., 2014).

The ANOVA results for comparison by age indicated higher resilience in social workers who were more advanced in age. Further, age showed a positive correlation with all the five factors of resilience. Age as a significant predictor of resilience has been elicited in an earlier study of trainee social workers (Kinman and Grant, 2011). Age also showed a negative relationship with anxiety levels in this study, indicating that with an increase in age, there is a decline in anxiety levels. These findings associated with age perhaps are suggestive of the role of work and life experiences that accrue with the advancement of age.

The duration of work experience was positively correlated with all five resilience factors and negatively with secondary traumatic stress. In terms of anxiety and compassion fatigue, ANOVA results showed higher scores for those with lesser years of work experience. These findings seem to suggest that the experience of anxiety and compassion fatigue declines with an increase in work experience and at the same time resilience also tends to increase. Thus, there seems to be a kind of maturing of professional attributes, the longer one has been in work. Whether this consequently translates into higher levels of professional competence, role performance and work efficacy cannot, however, be interpreted into these findings. These findings are in consonance with the extant literature relating to work experience which indicates that younger professionals in the helping services are at 
an elevated risk of compassion fatigue and burnout (Craig and Sprang, 2010; Knight, 2010; Schwartz, Tiamiyu, \& Dwyer, 2007; Hamama, 2012) and that compassion satisfaction increases with years of work experience (Arvay, 2001; Gentry, 2002; Sprang, Clark and Whitt-Woosley, 2007). A significant negative correlation between years in the profession and emotional exhaustion (burnout) has also been reported (Ray, Wong, White and Heaslip, 2013). It was also seen in this study that anxiety levels were higher for respondents for whom their current job was the first one.

We note from the results that anxiety and stress scores are positively correlated and that the five resilience factors also correlate significantly with the coping scores. This has also been reported in a study of social work students in India (Stanley and Mettilda, 2016). Further work stress scores correlated positively with anxiety levels, which in turn entered into a positive relationship with burnout scores. This corroborates the long-standing notion seen in the literature that underscores the relationship among these variables as manifested in social work practitioners (Dollard, 2003; Lloyd et al., 2002). It has been held that conflict between individual and organisational demands resulting in a reduced sense of achievement and accomplishment generates burnout over long periods of employment (Harr et al., 2014).

Our analysis also indicates that the effect of stress on burnout is moderated by the resilience scores. This finding is in congruence with the notion that resilience might buffer the negative impact of work stress, in intrinsically challenging working environments (Howard, 2008). Resilience is hence a key factor in enabling social workers to deal with work-related stress and consequently minimise the possibility of experiencing burnout.

\section{Implications for Intervention}

The findings of this study point to the need for a multi-pronged approach to enable social workers to deal more effectively with the complex demands of professional practice and to mitigate the deleterious consequences of work-related anxiety and stress. Previous writers have emphasised the need for the social work profession and all its stakeholders including practitioners, educational institutions and employers to deal proactively with burnout (Kim, Ji and Kao, 2011). The development of resilience is positively associated with managing adversity and 
enhancing professional competence when dealing with stressful situations encountered in practice (Menezes de Lucena et al., 2006). This study points out that developing resilience in social workers is important in this regard.

This could happen via three routes; one in terms of strengthening resilience and capacity building at an individual level; two dealing with organisational factors and three reforming current social work education and training. Intervention on an individual basis would include the strengthening of resilience by imparting stress management techniques, providing relevant work-related training and ensuring opportunities for professional growth and development. These measures have financial implications for employers but in the long run, could enhance work efficiency and employee retention.

The second route that we mentioned earlier is to take steps to modify organisational factors such as resource constraints, lack of autonomy, role ambiguity, increased workloads and the like. A positive organizational climate and constructive work culture are important determinants of job satisfaction (Glisson and James, 2002). Organizational strategies that promote a decentralized and supportive working environment is key in this regard (Kim and Stoner, 2008). Redesigning work to provide for greater autonomy in practice and enhancing social support are other measures that organisations need to consider (Dollard et al., 2000). Clinical supervision, the use of support and ongoing training are some organisational variables identified by social workers as ameliorating experiences associated with vicarious traumatization (Pack, 2014). Organizations must create a culture that appropriately responds to stress and manifestations of vicarious burnout in employees (Wilson, 2016). Social work agencies need to foster a work ethos that is supportive and growth oriented and takes into consideration factors that promote autonomy, realistic workloads and the provision of needed resources so that work efficacy is maximised as also staff morale and job satisfaction.

Social work education institutions also have an important role to play in terms of laying the foundations for professional competence that would then mature and grow with experience in practice. In our opinion, the process of recruitment and student selection has been undermined in recent years owing to the mushrooming growth of social work institutions in Tiruchirappalli, with each vying with others to recruit more 
students. This has resulted in the lack of proper screening to ascertain if students with the right kind of aptitude for social work, awareness of the rigour and realities of practice and the necessary resilience are being inducted into the profession. $A$ robust screening procedure during student intake is hence crucial to ascertain an applicant's resilience and awareness of the demands of the profession (Harr et al., 2014) and to ensure that square pegs are not being forcibly fit into round holes. The onus is also on academia in terms of imparting current knowledge and skills, but also ensuring that potential social workers are in tune with the realities of practice and preparing them to deal with stressors and vicarious trauma that they are likely to encounter. Inviting practitioners into the classroom to share practice experiences and anecdotes would be helpful in this regard. Training also requires the inculcation of stress management techniques and in areas such as budgeting and time management that could potentially enhance work competence and efficacy. The curriculum needs to have a sharper focus on the importance of self-care and prevention of compassion fatigue and burnout for trainee social workers (Bride and Figley, 2007; Hesse, 2002; Moore et al., 2011). Strategies to enable social work students to deal with the potential stress associated with traumatised people (Bride and Figley, 2007) and vulnerable groups is hence an important preparatory function of social work education. At present, the curriculum in India does not specifically focus on these aspects and issues such as compassion fatigue and burnout are rather cursorily dealt with. Activities that enable problem-solving, role-playing scenarios and simulated case analysis can enable better emotional management and need to be integrated with the curriculum.

Self-care is an important issue that needs to be emphasised in training programs and through a work culture that actively encourages the maintenance of wellbeing. Balanced nutrition, exercise, spirituality, taking a lunch break (away from the desk), or participation in stress-reducing activities are important (Newell and MacNeil, 2010). Involvement in activities that promote physical health and body fitness, relaxation and regeneration, creative expression, interpersonal relationships and spiritual practice are important aspects of self-care in managing compassion fatigue (Leon, Altholz, and Dziegielewski, 1999).

A combination of some of these measures will, in the long run, result in reduced anxiety and stress for social workers and enable them to deal more effectively with 
issues relating to compassion fatigue and burnout.

\section{Limitations}

A major limitation of this study is that the data has been collected only from women social workers and thus gender-based comparisons were not possible. Further, the study was conducted in only one city in India and given the vast nature of the country, the large size of the social work workforce and the heterogeneous settings of practice, does not constitute a representative sample. The data presented in this study is of a cross-sectional nature and reflects the attitudes and opinions of the respondents at the point of data collection and as such do not reveal the dynamics associated with job requirements and social work practice as they change over time. Yet another limitation of this study is that we have not considered organisational factors such as work ethos, supportive arrangements, workloads and other such aspects all of which play a significant role in determining the work experience of social workers.

\section{Conclusion}

Despite these limitations, this study makes an important contribution to the social work literature in India as previous investigations have not incorporated the wide array of variables that we have included in this study. It more specifically brings out the key role played by resilience in exerting a moderating influence between stress and burnout experienced by social workers in practice. This is a pointer to the fact that ameliorative measures to reduce work stress, strengthen resilience and reduce burnout can be taken so that the mental health and wellbeing of social workers can be enhanced. Strengthening coping strategies to enable social workers to deal more effectively with work-related stress and anxiety becomes relevant in this context. The findings indicate the need to adopt a training curriculum that will enhance professional competence by developing resilience and more effective strategies of coping. Organisational contexts are equally important to ameliorate the deleterious effects of work-related stress and to ensure that a supportive and nurturing work environment is provided by employers.

\section{Funding}

This research received no grant from any funding agency in the public, commercial, or not-for-profit sectors

Conflict of interest: None reported 


\section{References}

Adams RE, Boscarino JA and Figley CR (2006) Compassion fatigue and psychological distress among social workers: A validation study. American Journal of Orthopsychiatry 76(1): 103-108.

Alarcon G, Eschleman KJ and Bowling NA (2009) Relationships between personality variables and burnout: A meta-analysis. Work \& Stress 23 (3): 244-263.

Arvay MJ (2001) Secondary traumatic stress among trauma counsellors: What does the research say? International Journal for the Advancement of Counselling 23(4): 283-293.

Beer OWJ (2016) Predictors of and Responses to Stress Among Social Workers: A National Survey. PhD thesis, University of Plymouth, UK.

Bland JM and Altman DG (1995) Multiple significance tests: the Bonferroni method. British Medical Journal 310(6973): 170.

Bride BE and Figley CR (2007) The Fatigue of Compassionate Social Workers: An Introduction to the Special Issue on Compassion Fatigue. Clinical Social Work Journal 35(3):151-153.

Carver CS (1997) Brief Cope Scale You want to measure coping but your protocol too long: Consider the brief cope. International Journal of Behavioral Medicine 4(1): 92100.

Carver CS, Scheier MF and Weintraub JK (1989) Assessing Coping Strategies: A Theoretically Based Approach. Journal of Personality and Social Psychology 56(2): 267-83.

Chandran NSR (2017) Are the gains of social work profession reaching out to people in India effectively? International Journal of Multidisciplinary Research and Development 4(1): 111-114.

Coffey M, Samuel U, Collins S and Morris L (2012) A comparative study of social work students in India and the UK: stress, support and well-being. The British Journal of Social Work 44(1): 163-180.

Collins S (2008) Statutory Social Workers: Stress, Job Satisfaction, Coping, Social Support and Individual Differences. British Journal of Social Work 38(6): 1173-1193.

Collins S (2015) Alternative Psychological Approaches for Social Workers and Social Work Students Dealing with Stress in the UK: Sense of Coherence. British Journal of Social Work 45(1): 69-85.

Collins S (2017) Social Workers and Resilience Revisited. Practice 29(2): 85-105.

Connor KM and Davidson JR (2003) Development of a new Resilience Scale: The Connor-Davidson Resilience scale (CD-RISC). Depression and Anxiety 18(2):76-82. 
Craig CD and Sprang G (2010) Compassion satisfaction, compassion fatigue, and burnout in a national sample of trauma treatment therapists. Anxiety, Stress, \& Coping 23(3): 319-339.

De Croon EM, Sluiter JK, Blonk RWB, Broersen JPJ and Frings-Dresen MHW (2004) Stressful work, psychological job strain, and turnover: A two-year prospective cohort study of truck drivers. Journal of Applied Psychology 89(3): 442-454.

Dollard M F (2003) Conclusion. In: Dollard M F, Winefield A H and Winefield H R (eds) Occupational stress in the service professions. London: Taylor \& Francis, pp.409-415.

Dollard MF, Winefield HR, Winefield AH and de Jonge J (2000) Psychosocial job strain and productivity in human service workers: $A$ test of the demand-control-support model. Journal of Occupational and Organizational Psychology 73(4): 501-510.

Evans R, Pinnock K, Beirens H and Edwards A (2006) Developing Preventative Practices: the Experiences of Children, Young People and their Families in the Children's Fund. London: Department for Education and Skills

Figley C (ed) (2002) Treating compassion fatigue. New York: Brunner-Routledge.

Fletcher D and Fletcher J (2005) A meta-model of stress, emotions and performance: Conceptual foundations, theoretical framework, and research directions. Journal of Sports Sciences 23(2): 157-158.

Fletcher D and Sarkar M (2013) Psychological resilience: A review and critique of definitions, concepts, and theory. European Psychologist 18(1): 12-23.

Fletcher D and Scott M (2010) Psychological stress in sports coaches: a review of concepts, research, and practice. Journal of Sports Science 28(2):127-37.

Garcı'a-Secadez X, Molinero O, Salguero A, Rui'z BR, de la Vega R and Ma'rquez S (2016) Relationship Between Resilience and Coping Strategies in Competitive Sport. Perceptual and Motor Skills 122(1): 336-349.

Gentry JE (2002) Compassion Fatigue: A crucible of transformation. Journal of Trauma Practice 1(3): 37-61.

George D and Mallery P (2003) SPSS for Windows step by step: A simple guide and reference, (4th ed.). Boston, MA: Allyn \& Bacon.

Gil S and Weinberg M_(2015) Coping strategies and internal resources of dispositional optimism and mastery as predictors of traumatic exposure and of PTSD symptoms: A prospective study. Psychological Trauma 7(4): 405-411.

Glisson C and James LR (2002) The cross-level effects of culture and climate in human service teams. Journal of Organizational Behavior 23(6): 767-794.

Grant L and G Kinman (eds.) (2014) Developing Resilience for Social Work Practice. London: Palgrave.

Gray-Stanley JA and Muramatsu N (2011) Work stress, burnout, and social and personal resources among direct care workers. Research in Developmental Disabilities, 32 (3): 1065-1074. 
Hamama L (2012) Differences between Children's Social Workers and Adults' Social Workers on Sense of Burnout, Work Conditions and Organisational Social Support. The British Journal of Social Work, 42 (7): 1333-1353.

Harr CR, Brice TS, Riley K and Moore B (2014) The Impact of Compassion Fatigue and Compassion Satisfaction on Social Work Students. Journal of the Society for Social Work and Research 5(2): 233-251.

Harr C and Moore B (2011) Compassion Fatigue among Social Work Students in Field Placements. Journal of Teaching in Social Work 31(3): 350-363.

Hesse AR (2002) Secondary Trauma: How Working with Trauma Survivors Affects Therapists. Clinical Social Work Journal 30(3): 293-309.

Howard F (2008) Managing stress or enhancing wellbeing? Positive psychology's contributions to clinical supervision. Australian Psychologist 43(2): 105-113.

Howe D (2008) The Emotionally Intelligent Social Worker. London: Palgrave McMillan.

Humpel $\mathrm{N}$ and Caputi P (2001) Exploring the relationship between work stress, years of experience and emotional competency using a sample of Australian mental health nurses. Journal of Psychiatric and Mental Health Nursing 8(5): 399-403.

Jones SH (2005) A self-care plan for hospice workers. American Journal of Hospice and Palliative Medicine 22(2): 125-128.

Kim H and Stoner M (2008) Burnout and Turnover Intention among Social Workers: Effects of Role Stress, Job Autonomy and Social Support. Administration in Social Work 32(3): 5-25.

Kim H, Ji J and Kao D (2011) Burnout and Physical Health among Social Workers: A Three-Year Longitudinal Study. Social Work 56(3): 258-268.

Kinman G and Grant L (2011) Exploring Stress Resilience in Trainee Social Workers: The Role of Emotional and Social Competencies. British Journal of Social Work 41(2): 261-275.

Kinman G, McMurray I and Williams J (2014) Enhancing Self Knowledge, Coping Skills and Stress Resistance. In L. Grant and G.Kinman (eds) Developing Resilience for Social Work Practice. 148-168. London: Palgrave.

Knight C (2010) Indirect Trauma in the Field Practicum: Secondary Traumatic Stress, Vicarious Trauma, and Compassion Fatigue among Social Work Students and Their Field Instructors. Journal of Baccalaureate Social Work 15(1): 31-52.

Laming, Lord (2009) The Protection of Children in England: A Progress Report. London: The Stationery Office.

Law RW and Sabarra DA (2009) The effects of church attendance and marital status on the longitudinal trajectories of depressed mood among older adults. Journal of Aging and Health 21(6): 803-823. 
Lawson G and Myers JE (2011) Wellness, Professional Quality of Life, and Career Sustaining Behaviors: What Keeps Us Well? Journal of Counseling and Development, 89 (2): 163-171.

Lazarus R and Folkman S (1984) Stress Appraisal and Coping. New York: Springer.

Leon AM, Altholz JA, and Dziegielewski SF (1999). Compassion fatigue:

Considerations for working with the elderly. Journal of Gerontological Social Work 32(1): 43-62.

Lindstrom M (2009) Marital status, social capital, material conditions and self-rated health: a population-based study. Health Policy 93(2-3): 172-179.

Liu W, Wang J, Wang $\mathrm{H}$, Chen XY and Li JS (2018) The impact of stress and personality on resilience of patients with ulcerative colitis. Zhonghua Nei Ke Za Zhi 57(2): 107-111.

Lloyd C, King R and Chenoweth $L$ (2002) Social work, stress and burnout: A review. Journal of Mental Health 11(3): 255-265.

Lovibond F and Lovibond SH (1995) The structure of negative emotional states: Comparison of the Depression Anxiety Stress Scales (DASS) with the Beck Depression and Anxiety Inventories. Behaviour Psychology Research Therapy 33(3): 335-343.

Luthar SS (2006) Resilience in development: A synthesis of research across five decades. In: Cicchetti D and Cohen D J (eds) Developmental Psychopathology: Risk, Disorder, and Adaptation. New York: Wiley, pp. 740-795.

McGregor C (2015) History as a Resource for the Future: A Response to 'Best of times, worst of times: Social work and its moment', The British Journal of Social Work, 45 (5): 1630-1644.

Menezes de Lucena V, Fernández B, Hernández L, Ramos F and Contador I (2006) Resilience and personality in social work students and social workers. Psicothema 18(4): 791-796.

Montero-Marín J, García-Campayo J, Mera DM and del Hoyo LY (2009) A new definition of burnout syndrome based on Farber's proposal. Journal of Occupational Medicine and Toxicology 4(31): 1-17.

Moore SE, Bledsoe LK, Perry AR and Robinson MA (2011) Social work students and self-care: A model assignment for teaching. Journal of Social Work Education 47(3): 545-533.

Morazes JL, Benton AD, Clark SJ and Jacquet SE (2010) Views of specially trained child welfare social workers: A qualitative study of their motivations, perceptions, and retention. Qualitative Social Work 9(2): 227-247. 
Moriarty J, Baginsky M and Manthrope J (2015) Literature review of roles and issues within the Social Work profession in England. London: Professional Standards Authority.

Morrison T (2007) Emotional Intelligence, Emotion and Social Work: Context, Characteristics, Complications and Contribution. The British Journal of Social Work 37(2): 245-263.

Munro E (2011) The Munro review of child protection: Final report, a child-centred system. London: The Stationery Office.

Nair TK (2015) Social Work in India: A Semi-Profession. Social Work Footprints. Available at: http://www.socialworkfootprints.org/home/social-work-in-india-a-semiprofession (accessed 30 November 2017).

Newell JM and MacNeil GA (2010) Professional burnout, vicarious trauma, secondary traumatic stress, and compassion fatigue: A review of theoretical terms, risk factors, and preventative methods for clinicians and researchers. Best Practices in Mental Health 6(2): 57-68.

Pack M (2014) Vicarious Resilience: A Multilayered Model of Stress and Trauma. Journal of Women and Social Work 29(1): 18-29.

Quinn A, Ji P and Nackerud L (2018) Predictors of secondary traumatic stress among social workers: Supervision, income, and caseload size. Journal of Social Work. Epub ahead of print 27 March 2018. DOI: 10.1177/1468017318762450

Ravalier JM (2018) Psycho-Social Working Conditions and Stress in UK Social Workers, The British Journal of Social Work. Epub ahead of print 26 April 2018. DOI: 10.1093/bjsw/bcy023

Ray SL, Wong C, White D and Heaslip K (2013) Compassion Satisfaction, Compassion Fatigue, Work Life Conditions, and Burnout among Frontline Mental Health Care Professionals. Traumatology 19(4): 255-267.

Schraer R (2015) Social workers too stressed to do their job according to survey. Community Care, 7 January 2015. Available at:

http://www.communitycare.co.uk/2015/01/07/stress-stopping-job-social-workers- say/ (accessed 4 August 2018).

Schwartz RH, Tiamiyu MF and Dwyer DJ (2007) Social Worker Hope and Perceived Burnout: The Effects of Age, Years in Practice, and Setting. Administration in Social Work 31(4): 103-120.

Siddiqui HY (2001) Social Work Education: Some Unresolved Curriculum Issues. Indian Journal of Social Work 62(3): 535-553.

Simon CE, Pryce JG, Roff LL and Klemmack D (2006) Secondary traumatic stress and oncology social work: Protecting compassion from fatigue and compromising the worker's worldview. Journal of Psychosocial Oncology 23(4): 1-14. 
Simpkin AL, Khan A, West DC, Garcia BM, Sectish TC, Spector ND and Landrigan CP (2018) Stress from Uncertainty and Resilience Among Depressed and Burned Out Residents: A Cross-Sectional Study. Academic Pediatrics, Epub ahead of print 7 March 2018. DOI: 10.1016/j.acap.2018.03.002.

Smith B, Shatté A, Perlman A, Siers M and Lynch WD (2018) Improvements in Resilience, Stress, and Somatic Symptoms Following Online Resilience Training: A Dose-Response Effect. Journal of Occupational \& Environmental Medicine 60(1): 1-6.

Sprang G, Clark JJ and Whitt-Woosley A (2007) Compassion fatigue, compassion satisfaction, and burnout: Factors impacting a professional quality of life. Journal of Loss and Trauma 12 (3): 259-280.

Stamm BH (2005) Professional Quality of Life Scale: Compassion satisfaction, burnout and fatigue/ secondary trauma subscales-Revision IV. Available at: http://www.compassionfatigue.org/pages/ProQOLManualOct05.pdf (accessed 28 November 2017).

Stamm BH (2009) The Professional Quality of Life Scale (ProQOL) Available at: https://nbpsa.org/images/PRP/ProQOL_Concise_2ndEd_12-2010.pdf (accessed 28 November 2017).

Stamm BH (2010) Comprehensive Bibliography of the Effect of Caring for Those Who Have Experienced Extremely Stressful Events and Suffering. Available at: http://www.proqol.org/uploads/costs_of_caring_bib_11-2010.pdf (accessed 28 November 2017).

Stanley N Manthorpe J and White M (2007) Depression in the profession: Social workers' experiences and perceptions. British Journal of Social Work 37(2): 281 298.

Stanley S (2006) Social work education in Tamilnadu: issues of concern. In: Thavamani. M (ed.) Issues in Higher Education. Tiruchirappalli: Bharathidasan Univ. Pub., pp. 22-32.

Stanley S and Mettilda GB (2016) Reflective ability, empathy, and emotional intelligence in undergraduate social work students: a cross-sectional study from India. Social Work Education 35(5): 560-575.

Stanley S and Mettilda GB (2015) Stress, Anxiety, Resilience and Coping in Social Work Students (A Study from India). Social Work Education 35 (1): 78-88.

Thomas J (2013) Association of Personal Distress with Burnout, Compassion Fatigue and Compassion Satisfaction among Clinical Social Workers. Journal of Social Service Research 39(3): 365-379.

Weiss-Gal I and Welbourne P (2008) The professionalisation of social work: a crossnational exploration. International Journal of Social Welfare 17(4): 281-290.

Wilberforce M, Jacobs S, Challis D, Manthorpe J, Stevens M, Jasper R and ... Netten A (2014) Revisiting the causes of stress in social work: sources of job 
demands, control and support in personalised adult social care. British Journal of Social Work 44 (4): 812-830.

Willems EA (2014) Stress among Social Work Professionals in Mental Health Care Settings. Master of Social Work Clinical Research Papers. Paper 410. Available at: http://sophia.stkate.edu/msw_papers/410 (accessed 4 August 2018).

Wilson F (2016) Identifying, Preventing, and Addressing Job Burnout and Vicarious Burnout for Social Work Professionals. Journal of Evidence Informed Social Work 13(5):479-83.

Yoder EA (2010) Compassion fatigue in nurses. Applied Nursing Research 23(4):191197. 
Table 1

Distribution of respondents categorised as 'low' and 'high' based on mean scores for the key variables of the study

\begin{tabular}{|c|c|c|c|c|c|c|}
\hline Variables & Minimum & Maximum & Mean & SD & Low & High \\
\hline Stress & 0 & 21 & 5.68 & 4.24 & $66(55.0)$ & $54(45.0)$ \\
\hline Anxiety & 0 & 21 & 6.03 & 4.77 & $69(57.5)$ & $51(42.5)$ \\
\hline Resilience Factor 1 & 4 & 32 & 21.48 & 6.49 & $51(42.5)$ & $69(57.5)$ \\
\hline Factor 2 & 5 & 28 & 16.99 & 5.90 & $57(47.5)$ & $63(52.5)$ \\
\hline Factor 3 & 3 & 31 & 12.67 & 4.54 & $56(46.7)$ & $64(53.3)$ \\
\hline Factor 4 & 1 & 12 & 8.16 & 2.78 & $64(53.3)$ & $56(46.7)$ \\
\hline Factor 5 & 0 & 15 & 5.01 & 2.39 & $69(57.5)$ & $51(42.5)$ \\
\hline \multicolumn{7}{|l|}{ Emotion focussed } \\
\hline coping & 13 & 40 & 27.41 & 5.79 & $66(55.0)$ & $54(45.0)$ \\
\hline \multicolumn{7}{|l|}{ Problem focussed } \\
\hline coping & 8 & 24 & 16.93 & 3.59 & $57(47.5)$ & $63(52.5)$ \\
\hline \multicolumn{7}{|l|}{ Dysfunctional } \\
\hline coping & 11 & 40 & 24.99 & 5.88 & $60(50.0)$ & $60(50.0)$ \\
\hline Burnout & 15 & 50 & 29.53 & 5.90 & $60(50.0)$ & $60(50.0)$ \\
\hline \multicolumn{7}{|l|}{ Secondary } \\
\hline Traumatic Stress & 10 & 59 & 25.62 & 8.81 & $61(50.8)$ & $59(49.2)$ \\
\hline \multicolumn{7}{|l|}{ Compassion } \\
\hline Satisfaction & 14 & 50 & 34.10 & 7.40 & $58(48.3)$ & $62(51.7)$ \\
\hline
\end{tabular}

Note: Figures in parentheses are percentages 
Table 2

One way ANOVA summary table for subject dimensions by age of respondents

\begin{tabular}{llllll}
\hline Variables & Source & $\begin{array}{l}\text { Sum of } \\
\text { Squares }\end{array}$ & $\begin{array}{l}\text { Mean } \\
\text { Square }\end{array}$ & F & $\begin{array}{c}\text { Significance * } \\
\text { p }\end{array}$ \\
\hline Stress & BG & 104.38 & 34.79 & 1.99 & .121 \\
Anxiety & WG & 2037.59 & 17.57 & & \\
& BG & 162.91 & 54.30 & 2.48 & .065 \\
Resilience F1 & BG & 2544.96 & 21.94 & & \\
& WG & 429.34 & 243.11 & 6.59 & $.000^{*}$ \\
Resilience F2 & BG & 326.89 & 10.63 & & \\
& WG & 3814.10 & 32.88 & 3.31 & .023 \\
Resilience F3 & BG & 484.17 & 161.39 & 9.52 & $.000{ }^{*}$ \\
& WG & 1966.50 & 16.95 & & \\
Resilience F4 & BG & 125.64 & 41.88 & 6.13 & $.001^{*}$ \\
& WG & 792.36 & 6.83 & & \\
Resilience F5 & BG & 34.22 & 11.41 & 2.05 & .111 \\
& WG & 646.77 & 5.58 & & \\
Emotion & BG & 312.87 & 104.29 & 3.29 & .023 \\
Focused Coping & WG & 3682.12 & 31.74 & & \\
Problem & BG & 74.30 & 24.77 & 1.97 & .122 \\
Focused Coping & WG & 1458.03 & 12.57 & & \\
Dysfunctional & BG & 37.81 & 12.60 & .36 & .783 \\
Coping & WG & 4075.18 & 35.13 & & \\
Compassion & BG & 137.82 & 45.94 & .27 & .847 \\
Fatigue & WG & 20757.48 & 178.94 & & \\
Compassion & BG & 301.24 & 100.41 & 1.87 & .138 \\
Satisfaction & WG & 6221.56 & 53.63 & & \\
\hline
\end{tabular}

$N=120 ; d f=3,116 ;{ }^{*}$ Bonferroni Corrected $p=0.004$ 
Table 3

t tests for respondents on select background factors by key variables

\begin{tabular}{|c|c|c|c|c|c|c|c|c|c|}
\hline \multirow[b]{2}{*}{ Variable } & \multirow[b]{2}{*}{ Group } & \multicolumn{2}{|c|}{ Marital Status } & \multicolumn{2}{|c|}{ Type of family } & \multicolumn{2}{|c|}{ Nature of job } & \multicolumn{2}{|c|}{ Current job } \\
\hline & & $\begin{array}{l}\text { Married } \\
n=70\end{array}$ & $\begin{array}{l}\text { Unmarried } \\
\mathrm{n}=50\end{array}$ & $\begin{array}{l}\text { Joint } \\
n=28\end{array}$ & $\begin{array}{l}\text { Nuclear } \\
n=92\end{array}$ & $\begin{array}{l}\text { Permanent } \\
n=19\end{array}$ & $\begin{array}{l}\text { Temporary } \\
n=101\end{array}$ & $\begin{array}{l}\text { First job } \\
n=58\end{array}$ & $\begin{array}{l}\text { Not first job } \\
n=62\end{array}$ \\
\hline & Mean & 5.27 & 6.26 & 5.61 & 5.71 & 4.32 & 5.94 & 6.59 & 4.84 \\
\hline \multirow[t]{3}{*}{ Stress } & SD & 3.72 & 4.86 & 4.04 & 4.32 & 3.13 & 4.39 & 4.22 & 4.12 \\
\hline & $\mathrm{t}$ & \multicolumn{2}{|c|}{$-1.26(p>.05)$} & \multicolumn{2}{|c|}{$-.10(p>.05)$} & \multicolumn{2}{|c|}{$-1.54(p>.05)$} & \multicolumn{2}{|c|}{$2.29(p<.05)$} \\
\hline & Mean & 5.66 & 6.56 & 6.68 & 5.84 & 4.95 & 6.24 & 7.09 & 5.05 \\
\hline \multirow[t]{3}{*}{ Anxiety } & SD & 4.51 & 5.11 & 5.69 & 4.47 & 3.91 & 4.91 & 4.86 & 4.50 \\
\hline & $\mathrm{t}$ & \multicolumn{2}{|c|}{$-1.02(p>.05)$} & \multicolumn{2}{|c|}{$.82(p>.05)$} & \multicolumn{2}{|c|}{$-1.08(p>.05)$} & \multicolumn{2}{|c|}{$2.38(p<.05)$} \\
\hline & Mean & 69.34 & 57.26 & 63.96 & 64.41 & 73.05 & 62.66 & 61.00 & 67.40 \\
\hline \multirow[t]{2}{*}{ Resilience } & SD & 16.19 & 20.25 & 17.82 & 19.29 & 9.95 & 19.73 & 19.78 & 17.60 \\
\hline & $\mathrm{t}$ & \multicolumn{2}{|c|}{$3.62(p<.001)$} & \multicolumn{2}{|c|}{$-.11(p>.05)$} & \multicolumn{2}{|l|}{$2.24(p<.05)$} & \multicolumn{2}{|c|}{$-1.88(p>.05)$} \\
\hline Emotion & Mean & 28.41 & 26.00 & 27.07 & 27.51 & 28.84 & 27.14 & 26.79 & 27.98 \\
\hline focussed & SD & 5.43 & 6.04 & 6.33 & 5.65 & 3.91 & 6.06 & 5.68 & 5.88 \\
\hline coping & $\mathrm{t}$ & \multicolumn{2}{|c|}{$2.29(p<.05)$} & \multicolumn{2}{|c|}{$-.35(p>.05)$} & \multicolumn{2}{|l|}{$1.18(p>.05)$} & \multicolumn{2}{|c|}{$-1.13(p>.05)$} \\
\hline Problem & Mean & 17.47 & 16.16 & 17.32 & 16.80 & 17.89 & 16.74 & 16.59 & 17.24 \\
\hline focussed & SD & 3.42 & 3.72 & 3.62 & 3.59 & 2.05 & 3.79 & 3.81 & 3.37 \\
\hline coping & $\mathrm{t}$ & \multicolumn{2}{|c|}{$1.99(p<.05)$} & \multicolumn{2}{|c|}{$.67(p>.05)$} & \multicolumn{2}{|l|}{$1.29(p>.05)$} & \multicolumn{2}{|c|}{$-1.00(p>.05)$} \\
\hline Dysfunctional & Mean & 24.87 & 25.16 & 24.21 & 25.22 & 26.26 & 24.75 & 24.34 & 25.60 \\
\hline \multirow[t]{2}{*}{ coping } & SD & 5.91 & 5.89 & 5.81 & 5.91 & 4.21 & 6.13 & 5.70 & 6.02 \\
\hline & $\mathrm{t}$ & \multicolumn{2}{|c|}{$-.26(p>.05)$} & $-.80(p$ & $.05)$ & $1.03(p>.05)$ & & $-1.17(p>$ & 5) \\
\hline Compassion & Mean & 56.04 & 53.30 & 55.64 & 54.67 & 55.26 & 54.83 & 55.55 & 54.29 \\
\hline fatigue & SD & 13.33 & 11.62 & 12.86 & 12.67 & 11.39 & 12.95 & 12.81 & 12.61 \\
\hline & $\mathrm{t}$ & $1.17(p>$ & & $.35(p>$ & 05) & $.14(p>.05)$ & & $.54(p>.0$ & \\
\hline Compassion & Mean & 34.71 & 33.24 & 32.50 & 34.59 & 34.26 & 34.07 & 33.88 & 34.31 \\
\hline satisfaction & SD & 7.10 & 7.80 & 8.73 & 6.93 & 6.87 & 7.53 & 7.42 & 7.44 \\
\hline & $\mathrm{t}$ & $1.07(p>$ & 05) & -1.31( & $>.05)$ & $.11(p>.05)$ & & $-.32(p>$. & \\
\hline
\end{tabular}


Table 4

Inter-correlation matrix for respondents on key variables of the study.

\begin{tabular}{|c|c|c|c|c|c|c|c|c|c|c|c|c|c|c|c|c|c|}
\hline & Variable & 1 & 2 & 3 & 4 & 5 & 6 & 7 & 8 & 9 & 10 & 11 & 12 & 13 & 14 & 15 & 16 \\
\hline 1 & Age & 1 & $.76^{* *}$ & $41^{* *}$ & -.03 & $-.23^{*}$ & $.40^{* *}$ & $.31^{* *}$ & $.45^{* *}$ & $.35^{* *}$ & $.18^{*}$ & $.18^{*}$ & .12 & .12 & .07 & -.10 & .14 \\
\hline 2 & $\begin{array}{l}\text { Years of } \\
\text { Experience }\end{array}$ & $.76^{* *}$ & 1 & $.33^{* *}$ & .05 & -.17 & $.27^{* *}$ & $.22^{*}$ & $.35^{* *}$ & $.23^{*}$ & $.20^{*}$ & .08 & .04 & .15 & .01 & $-.18^{*}$ & .15 \\
\hline 3 & $\begin{array}{l}\text { Monthly } \\
\text { Income }\end{array}$ & $.41^{* *}$ & $.33^{* *}$ & 1 & -.11 & $-.24^{* \star}$ & .13 & $.20^{*}$ & $.21^{*}$ & $.19^{*}$ & $.19^{*}$ & -.02 & -.05 & $-.19^{*}$ & $-.20^{*}$ & -.02 & -.17 \\
\hline 4 & Stress & -.03 & .05 & -.11 & 1 & $.47^{* *}$ & -.12 & -.09 & -.14 & -.01 & -.05 & .02 & .01 & -.02 & 13 & $.28^{* *}$ & -.04 \\
\hline 5 & Anxiety & $-.23^{*}$ & -.17 & $-.24^{* *}$ & $.47^{* *}$ & 1 & -.02 & .02 & -.08 & .06 & -.05 & $.19^{*}$ & $.18^{*}$ & .08 & $.26^{\star *}$ & $.48^{* *}$ & -.07 \\
\hline 6 & Resilience F1 & $.40^{* *}$ & $.27^{* *}$ & .13 & -.12 & -.02 & 1 & $.70^{* *}$ & $.74^{* *}$ & $.70^{* *}$ & $.54^{* *}$ & $.58^{* *}$ & $.64^{* *}$ & $.29^{* *}$ & $.32^{\star *}$ & -.01 & $.41^{* *}$ \\
\hline 7 & Resilience F2 & $.31^{* *}$ & $.22^{*}$ & $.20^{*}$ & -.08 & .02 & $.70^{* *}$ & 1 & $.70^{* *}$ & $.69^{* *}$ & $.50^{* *}$ & $.49^{* *}$ & $.56^{* *}$ & $.35^{* *}$ & $.29^{* *}$ & -.02 & $.39^{* *}$ \\
\hline 8 & Resilience F3 & $.45^{* *}$ & $.35^{* *}$ & $.21^{*}$ & -.14 & -.08 & $.74^{* *}$ & $.70^{* *}$ & 1 & $.69^{* *}$ & $.48^{* *}$ & $.45^{* *}$ & $.49^{* *}$ & $.22^{*}$ & $.25^{\star \star}$ & -.02 & $.34^{* *}$ \\
\hline 9 & Resilience F4 & $.35^{* *}$ & $.23^{*}$ & $.19^{*}$ & -.01 & .06 & $.70^{* *}$ & $.69^{* *}$ & $.69^{* *}$ & 1 & $.42^{* *}$ & $.52^{* *}$ & $.61^{* *}$ & $.22^{*}$ & $.25^{\star \star}$ & .07 & $.40^{* *}$ \\
\hline 10 & Resilience F5 & $.18^{*}$ & $.20^{*}$ & $.19^{*}$ & -.05 & -.05 & $.54^{* *}$ & $.50^{* *}$ & $.48^{* *}$ & $.42^{* *}$ & 1 & $.47^{* *}$ & $.48^{* *}$ & $.33^{* *}$ & $.24^{* *}$ & .02 & $.35^{* *}$ \\
\hline 11 & $\begin{array}{l}\text { Emotion Focussed } \\
\text { Strategies }\end{array}$ & $.19^{*}$ & .08 & -.02 & .02 & $.19^{*}$ & $.58^{* *}$ & $.49^{* *}$ & $.45^{* *}$ & $.52^{* *}$ & $.47^{* *}$ & 1 & $.79^{* *}$ & $.26^{* *}$ & $.39^{\star *}$ & $.21^{*}$ & $.42^{* *}$ \\
\hline 12 & $\begin{array}{l}\text { Problem Focussed } \\
\text { Strategies }\end{array}$ & .12 & .04 & -.05 & .01 & $.18^{*}$ & $.64^{* *}$ & $.56^{* *}$ & $.49^{* *}$ & $.61^{* *}$ & $.48^{* *}$ & $.79^{* *}$ & 1 & $.32^{* *}$ & $.42^{* *}$ & $.19^{*}$ & $.43^{* *}$ \\
\hline 13 & $\begin{array}{l}\text { Dysfunctional } \\
\text { Coping }\end{array}$ & .02 & .15 & $.19^{*}$ & -.02 & .08 & $.29^{* *}$ & $.35^{* *}$ & $.22^{*}$ & $.22^{*}$ & $.33^{* *}$ & $.26^{* *}$ & $.32^{* *}$ & 1 & .17 & -.03 & $.25^{* *}$ \\
\hline 14 & Burnout & .07 & .01 & $.20^{*}$ & .13 & $.26^{* *}$ & $.32^{\star *}$ & $29^{\star *}$ & $.25^{\star *}$ & $.25^{\star *}$ & $24^{\star *}$ & $39^{* *}$ & $.42^{\star *}$ & .17 & 1 & $.61^{* *}$ & $.52^{* *}$ \\
\hline 15 & $\begin{array}{l}\text { Secondary } \\
\text { Traumatic Stress }\end{array}$ & -.10 & $-.18^{*}$ & .02 & $.28^{* *}$ & $.48^{* *}$ & -.01 & -.02 & -.02 & .07 & .02 & $.21^{*}$ & $.19^{*}$ & -.03 & $.61^{* *}$ & 1 & .18 \\
\hline 16 & $\begin{array}{l}\text { Compassion } \\
\text { Satisfaction }\end{array}$ & .14 & .15 & .17 & -.04 & -.07 & $.41^{* *}$ & $.39^{* *}$ & $.34^{* *}$ & $.40^{* *}$ & $.35^{* *}$ & $.42^{* *}$ & $.43^{* *}$ & $.25^{* *}$ & $.52^{* *}$ & $.18^{*}$ & 1 \\
\hline
\end{tabular}

Correlation (2-tailed) is significant at the 0.01 level ** and at the 0.05 level * 